\title{
A decision support system for evaluating effects of feed-in tariff mechanism: dynamic modeling of Malaysia's electricity generation mix
}

\begin{abstract}
Malaysia has abundant potentials of renewable energy resources mainly because of its rich agriculture that makes high potential in bio-power and its tropical climate, which provides sufficient sunlight for utilization of solar systems. Feed in Tariff mechanism has been applied since 2011 in Malaysia to expand utilization of renewable energy for electricity generation. In this study, a broad range of data is gathered to develop a comprehensive system dynamics model to evaluate the impacts of Feed in Tariff mechanism on the generation mix of Malaysia during a 20-year period between 2011 and 2030. Results demonstrate that although the policy may lead to a satisfactory level of target achievement but the Malaysian government may face an increasing shortage in its RE fund budget starting around 2019 unless it increases its income sources by rising the surcharges on electricity bills or decreases its expenditures by optimizing the amount of FiT payments in different periods. The sensitivity analysis illustrates that the more funding will not lead to a more sustainable generation mix unless it is paid in the right time and in the right direction. Using this model, policymakers can carry out analysis to determine the amount of money that must be collected from the electricity consumers through the surcharges on electricity bills as well as the amount of feed in tariff to be paid for different renewable resources in different periods.
\end{abstract}

Keyword: System dynamics; Feed in tariff; Energy policy; Decision support system; Electricity generation modelling 